\title{
Targeting of Rad5 I-dependent homologous recombination: implications for the radiation sensitivity of human lung cancer cell lines
}

\author{
A Sak', , G Stueben', M Groneberg', W Böcker ${ }^{2}$ and M Stuschke' \\ 'Department of Radiotherapy, University Hospital Essen, 45122 Essen, Germany; ${ }^{2}$ Institute of Medical Radiation Biology, University Hospital Essen, \\ 45122 Essen, Germany
}

\begin{abstract}
The aim of the present work was to study the role of Rad5I-dependent homologous recombination in the radiation response of non-small-cell lung cancer (NSCLC) cell lines. A dose- and time-dependent increase in the formation of Rad5 I and $\gamma$-H2AX foci with a maximum at about 4 and I h after irradiation, followed by a decrease, has been found. The relative fraction of cells with persisting Rad5 I foci was $20-30 \%$ in radioresistant and $60-80 \%$ in radiosensitive cell lines. In comparison, a higher fraction of residual Dsb was evident in cell lines with nonfunctional p53. Transfection with As-Rad5 I significantly downregulates radiation-induced formation of Rad5 I foci and increases apoptosis, but did not influence the rejoining of DNA double-strand breaks. Interestingly, wortmannin, a well-known inhibitor of nonhomologous end-joining, also inhibits Rad5 I foci formation. In general, there was no correlation between the clonogenic survival at $2 \mathrm{~Gy}$ and the percentage of initial Rad5I or $\gamma-\mathrm{H} 2 \mathrm{AX}$ foci after ionising radiation (IR). The most reliable predictive factor for radiosensitivity of NSCLC cell lines was the relative fraction of Rad5I foci remaining at $24 \mathrm{~h}$ after IR. Although most of the Rad5 I foci are co-localised with $\gamma-\mathrm{H} 2 \mathrm{AX}$ foci, no correlation of the relative fraction of persisting $\gamma-\mathrm{H} 2 \mathrm{AX}$ foci and SF2 is evident.
\end{abstract}

British Journal of Cancer (2005) 92, 1089 - 1097. doi:I0.1038/sj.bjc.6602457 www.bjcancer.com

Published online 22 March 2005

(c) 2005 Cancer Research UK

Keywords: Rad5I; H2AX; p53; DNA double-strand break repair; apoptosis; lung cancer

Among the various forms of DNA damage induced by ionising radiation (IR), DNA double-strand breaks (Dsb) are the most lethal. Recognition and repair of Dsb is therefore a critical step in irradiated cells. In eukaryotes, DNA double-strand breaks (Dsb) can be repaired either by nonhomologous end-joining (NHEJ) mechanism or by homologous directed repair (Kanaar et al, 1998; Johnson and Jasin, 2001). An important repair protein responsible for NHEJ is DNA-dependent protein kinase (DNA-PK), a serinethreonine protein kinase consisting of three subunits (DNA-PKcs, $\mathrm{Ku} 70$ and Ku80). Cells with reduced DNA-PK activity due to a defect in any of the subunits are deficient in the rejoining of radiation-induced DNA Dsb and are radiosensitive in the clonogenic assay (Leuther et al, 1999; Smith and Jackson, 1999). On the other hand, Rad51 protein, a member of the Rad52 epistasis group, plays an essential role exclusively in homologous recombination (HR) in mammalian cells. The Rad51 protein is essential for the viability of mammals and vertebrates as mouse embryos and chicken cells with homozygous Rad51 deletion are not viable (Tsuzuki et al, 1996; Sonoda et al, 1998). Lethality of Rad51(-I-) mouse embryos was thought to be a consequence of p53dependent apoptotic death of growing cells with accumulated spontaneous Dsb that are unrepaired by HR. Double mutants of

*Correspondence: Dr A Sak; E-mail: ali.sak@uni-essen.de Received 16 August 2004; revised 5 January 2005; accepted 19 January 2005; published online 22 March 2005
Rad51(-/-) and p53(-/-) mice live longer due to the lack of p53dependent apoptotic cell death. In general, the expression level of Rad51 correlates with the fraction of cycling cells (Shinohara $e t a l$, 1993; Yamamoto et al, 1996) and elevated levels of Rad51 protein was found in tumour cells as compared with normal cells (Raderschall et al, 2002a).

In human lymphocytes in the growing phase and in a low number of normal cultured mammalian cells, the Rad51 is detected in multiple nuclear foci, that is, focally concentrated immunofluorescence signals (Tashiro et al, 1996). These foci are thought to correspond to Rad51 containing nucleoprotein filaments in the Dsb recombination process (Haaf et al, 1995; Yamamoto et al, 1996) and contain the ssDNA-binding replication protein A (RPA), Rad52 and Rad54 (Golub et al, 1998; Gupta et al, 1998; Liu et al, 1999; Tan et al, 1999). Ionising-radiation-induced DNA damage increases the percentage of cells with Rad51 foci in a dose- and time-dependent manner, with a maximum at about 3-6h after irradiation (Bishop et al, 1998). Therefore, a timely co-ordinated action of NHEJ and HR in mammalian cells is obviously, with a fast but error-prone (NHEJ) and a slow but error-free (HR) repair pathways (van Gent et al, 2001). A cell-cycle-dependent effect of Rad51 protein accumulation has been shown, with a peak in the $S$ and G2 phases, in which the repair of Dsb primarily takes place via homologous recombination (Flygare et al, 1996). A number of approaches have shown that reduction in Rad51 levels via antisense oligonucleotides (Taki et al, 1996; Ohnishi et al, 1998), 
ribozymes (Collis et al, 2001) or drugs (Russell et al, 2003) increased the radiation sensitivity of tumour cell lines.

Given the role of DNA repair in the radioresponse of human tumour cells and the presence of two main repair pathways, we previously studied the role of DNA-PK-dependent NHEJ in the radiosensitivity of non-small-cell lung cancer (NSCLC) and have shown that reduced DNA-PK activity decreased the rejoining of radiation-induced DNA Dsb and increased the radiosensitivity (Sak et al, 2002). In the present study, the role of HR in the radioresponse of the same cell lines has been evaluated. We used As-oligodeoxynucleotide (ODN) specific for Rad51 mRNA in order to analyse its effect on Rad51-foci formation, rejoining of radiation induced DNA-Dsb and apoptosis in NSCLC cell lines. One of the earliest steps in the cellular response to DSBs is the phosphorylation of serine 139 of $\gamma-\mathrm{H} 2 \mathrm{AX}$. A quantitative similarity between the induction and repair of DSBs and the formation and disappearance of $\gamma$-H2AX foci has been found (Banath et al, 2004). Thus, we used $\gamma$-H2AX foci formation and a gel-electrophoresis assay to determine whether persisting Rad51 foci were indicative of nonrepaired Dsb.

\section{MATERIALS AND METHODS}

\section{Cell culture and irradiation of cells}

The NSCLC cell lines H460, H520 and H661 were obtained from the American Type Culture Collection (ATCC, Rockville, MD, USA) and were grown in RPMI 1640 containing $10 \%$ foetal calf serum, and $100 \mathrm{U} \mathrm{ml}^{-1}$ penicillin/streptomycin under an atmosphere of $5 \% \mathrm{CO}_{2}, 95 \%$ air at $37^{\circ} \mathrm{C}$. The NSCLC cell line A549 was obtained from DSZM (Braunschweig, Germany) and was grown in Eagle's minimal essential medium (MEM) supplemented with $15 \%$ foetal calf serum, non-essential amino acids and penicillin/ streptomycin ( $100 \mathrm{U} \mathrm{ml}^{-1}$, all from Gibco-BRL, Paisley, UK). Cultures were irradiated with a ${ }^{60} \mathrm{Co}$ source at $3.2 \mathrm{~Gy} \mathrm{~min}{ }^{-1}$. Controls were mock irradiated. Measurement of clonogenic survival following irradiation of G1-enriched cells with $2 \mathrm{~Gy}$ (SF2), synchronisation of cells in the G1 and S/G2 phases of the cell cycle, and the fraction of apoptotic cells after staining with Hoechst-33342 (Sigma, Taufkirchen, Germany) was performed as previously described (Stuschke et al, 2002).

\section{Oligodeoxynucleotides}

An antisense ODN targeting the Rad51 messenger RNA, one ODN with reverse orientation to Rad51 and one unrelated (UR) ODN were synthesised and purified by BioTez (Berlin, Germany). A BLASTN search of a database containing all sequences in the National Center for Biotechnology information (NCBI) database revealed no homology of the ODNs to other human genes. All oligonucleotides were phosphorothioates purified by high-pressure liquid chromatography. The sequences derived from a cDNA sequence (gene accession number U47077 from NCIB) were as follows: As-Rad51: 5'-CTG.CAT.CTG.CAT.TGC.CAT.TA-3' (nucleotides: 231-250), gene accession number D14134 from NCIB; Sense-Rad51: 5'-TAA.TGG.CAA.TGC.AGA.TGC.AG-3', ScrambleRad51: 5'GTC.TCA.GTC.CAT.TCT.ACT.A-3'. In order to control for unspecific effects of GG strings (Burgess et al, 1995) an UR sequence composition, 5'-AAG.AGA.GGT.CCG.AGG.AGG.GG-3' (Iotsova and Stehelin, 1995) was also used. As-ODN targeting DNA-PKcs (Sak et al, 2002) was used in order to modulate NHEJ.

\section{Lipid-mediated transfection of antisense ODNs}

Cells were plated in $9.6 \mathrm{~cm}^{2}$ culture dishes (Beckton Dickinson, Heidelberg, Germany) at a density of about $2 \times 10^{4}$ cells cm $\mathrm{cm}^{-2}$ for $\mathrm{H} 661$ and $4 \times 10^{4}$ cells $\mathrm{cm}^{-2}$ for the $\mathrm{H} 460$ and A549 cell lines. Transfections were carried out at $20 \mathrm{~h}$ after plating when cells reached a confluence of $50-80 \%$ as previously described (Sak et al, 2002).

\section{Immunofluorescence staining}

Rad51 Cells were harvested and seeded in chamber slides and irradiated at $6 \mathrm{~h}$ for G1-enriched and at $24 \mathrm{~h}$ for exponential growing populations. Transfected cells were harvested at $20 \mathrm{~h}$ after the beginning of transfection, seeded in chamber slides and irradiated $6 \mathrm{~h}$ later. At specified times after irradiation, cells were fixed in $4 \%$ paraformaldehyde for $15 \mathrm{~min}$ at room temperature (RT), washed with PBS, followed by treatment in P-buffer $(100 \mathrm{~mm}$ Tris- $\mathrm{HCl}, \mathrm{pH} 7.4 ; 50 \mathrm{~mm}$ EDTA, 0.5\% Triton X-100) for $15 \mathrm{~min}$ at $\mathrm{RT}$, and washed twice in PBS. After incubation in blocking buffer ( $3 \%$ BSA, $0.1 \%$ Tween $20,4 \times \mathrm{SSC}$ ) for at least $24 \mathrm{~h}$ at $4^{\circ} \mathrm{C}$, the primary Rad51 (Ab-1, Oncogene Research Products, San Diego, CA, USA) at a dilution of $1: 500$ in PBS was added and incubated for $20 \mathrm{~h}$ at $4{ }^{\circ} \mathrm{C}$ or $90 \mathrm{~min}$ at RT. After washing in PBS, cells were incubated with a Cy3-labelled secondary antibody (goat-antirabbit, at a dilution of 1:500 in PBS) for $90 \mathrm{~min}$ at RT and washed twice in PBS.

$\gamma-H 2 A X$ For the most parts, immunostaining procedure for $\gamma$ $\mathrm{H} 2 \mathrm{AX}$ foci detection was the same as described for Rad51. Cells were incubated with $\gamma-\mathrm{H} 2 \mathrm{AX}$ antibody (anti-phospho-histone H2AX (Ser139), Upstate, NY, USA) at a dilution of $1: 100$ in PBS for $20 \mathrm{~h}$ at $4{ }^{\circ} \mathrm{C}$. After washing in PBS, cells were incubated with Alexa 488-labelled secondary antibody (goat-anti-mouse, at a dilution of $1: 300$ in PBS) for $2 \mathrm{~h}$ at RT and washed twice in PBS. Cells were incubated in the dark with $4^{\prime}$,6-diamidino-2-phenylindole (DAPI, $0.6 \mu \mathrm{g} \mathrm{ml}^{-1}$ in PBS) for $10 \mathrm{~min}$ and coverslips were mounted in immu-mount (Shandon, Pittsburgh, PA, USA).

For conventional immunofluorescence microscopy, the cells were examined with a Zeiss Axioskop fluorescence microscope (Wetzlar, Germany) equipped with a CCD camera CS15/4MCC (Kappa Messtechnik GmbH, Gleichen, Germany). Images were captured and imported into an image analysis software package Image $\mathrm{C}$ (Imtronic $\mathrm{GmbH}$, Berlin, Germany). In some cases images were merged using Photoshop 7.0 software (Adobe Systems Inc, USA). For quantitative analysis, nuclei were analysed by eye during the imaging process. At least 100 cells were selected at random and were counted to calculate the percentages of cells containing $>5$ Rad51 foci per nuclei. Alternatively, fluorescent images were collected with a confocal laser-scanning microscope (Leica DM IRE2, Wetzlar, Germany). For the quantitative analysis of the number of $\gamma-\mathrm{H} 2 \mathrm{AX}$ foci per nuclei, about $10-20$ cells per experiment were scored. For the analysis of Rad51 and $\gamma$-H2AX foci co-localisation, about 10-20 random cells per experiment that were scored as containing Rad51 foci were counted, analysed for $\gamma$ $\mathrm{H} 2 \mathrm{AX}$ co-localisation and the results from at least three different experiments were averaged.

\section{Induction and repair of DNA double-strand breaks with the FAR assay}

Cells were irradiated with $30 \mathrm{~Gy}$ at $4{ }^{\circ} \mathrm{C} 20-24 \mathrm{~h}$ following transfection and were serially sampled at 0,1 and $4 \mathrm{~h}$ after incubation at $37^{\circ} \mathrm{C}$ and cast into plug moulds. Cell lysis and electrophoresis were performed as described previously (Stuschke et al, 2002). The fraction of DNA released from the plugs into the gel (FAR) as a measure for DNA-Dsb was calculated according to the formula $\mathrm{FAR}=$ (intensity in the lane)/(intensity in the lane + intensity in the well).

\section{Detection of mRNA by Northern blot analysis}

At 20-24h following transfection, cells were harvested mechanically and washed once with PBS. Cell lysis and electrophoresis were 
performed as previously described (Sak et al, 2002). A PCRamplified $1.15 \mathrm{kbp}$ Rad51 fragment (Xia et al, 1997) was the specific probe for Rad51. For the synthesis of this probe, primers P1 (5'-TAG.AGA.AGT.GGA.GCG.TAA.GC-3') and P2 (5'-ACC.CAA.TGA.TTC.AGT.CTT.TG-3') were used. As a control for loading error and overall mRNA transcription activity, a plasmid probe for the $\beta$-actin gene was used (Ambion). Signals for each lane with Rad51 were normalised to the $\beta$-actin signals of the same lane.

\section{Western blot analysis}

Cell lysis and electrophoresis were performed as described previously (Sak et al, 2003). Briefly, aliquots of total cell lysates $(40 \mu \mathrm{g})$ were resolved in $4-12 \%$ precasted polyacrylamide-SDS gels, and subjected to Western blot analysis using Rad51 (Oncogene Research Products, San Diego, CA, USA), $\beta$-actin (sc-1616-R, Santa Cruz Biotechnology, CA, USA) antibodies. Bound antibodies were detected by incubation with horseradish peroxidase (HRP)-conjugated secondary antibody, followed by enhanced chemiluminescence (Amersham, Germany) and autoradiography.

\section{Data evaluation}

All experiments were repeated at least three times, and the data are given as a mean \pm standard error margin (s.e.m.) for the independent experiments. Statistical analysis (two-sided $t$-test) and graphs were performed with the aid of Microcal Origin version 7.0 (Microcal Software, Northampton, MA, USA).

\section{RESULTS}

Expression and modulation of repair complexes containing locally concentrated Rad51 foci

The ability for the formation of Rad51 foci has been evaluated in exponentially growing and G1-enriched NSCLC cell lines with functional (A549, H460) and nonfunctional p53 (H661, H520). In exponentially growing populations, only a small percentage of nonirradiated cells with $1.7 \pm 0.4,8.9 \pm 1.5,5.2 \pm 2.5$ and $6.2 \pm 2.6 \%$ of H460, A549, H661 and H520, respectively, showed more than five Rad51 protein foci per nucleus. In comparison, the percentage of cells with focally concentrated Rad51 foci increases in a doseand time-dependent manner after IR, with a maximum at about $4 \mathrm{~h}$. Figure 1 shows the percentage of Rad51-presenting nuclei at $4 \mathrm{~h}$ after irradiation with $0-30 \mathrm{~Gy}$. The respective values are $85.0 \pm 2.0,57.0 \pm 8.8,61.2 \pm 7.1$ and $75.6 \pm 8.7 \%$ for H460, A549, H661 and H520 cells irradiated with $30 \mathrm{~Gy}$. The fraction of nuclei with Rad51 foci and the number of foci per nuclei increases with increasing radiation doses. In contrast to exponentially growing cells, the fraction of Rad51 foci in G1-enriched populations was very low with $\leqslant 1 \%(\mathrm{~A} 549, \mathrm{H} 460)$ and $\leqslant 5 \%(\mathrm{H} 661, \mathrm{H} 520)$ without a significant effect of IR. At $24 \mathrm{~h}$ after irradiation, the number of foci per nucleus and the fraction of cells with Rad51 foci decreases (Figure 2, Table 1), showing that repair has taken place within this time interval. However, there was a difference in the fraction of Rad51 foci presenting cells at $24 \mathrm{~h}$ between the cell lines studied with $<40 \%$ of the maximum level in IR resistant (A549, H661) and $>60 \%$ in sensitive cell lines (H460, H520).

\section{Relation between Rad5 foci, $\gamma-\mathrm{H} 2 \mathrm{AX}$ foci and residual DNA double-strand breaks}

To determine whether persisting Rad51 foci at $24 \mathrm{~h}$ after irradiation were indicative of nonrepaired DNA double-strand breaks, $\gamma-\mathrm{H} 2 \mathrm{AX}$ immunostaining and the FAR assay were used to evaluate the induction and repair of Dsb in NSCLC cell lines. The

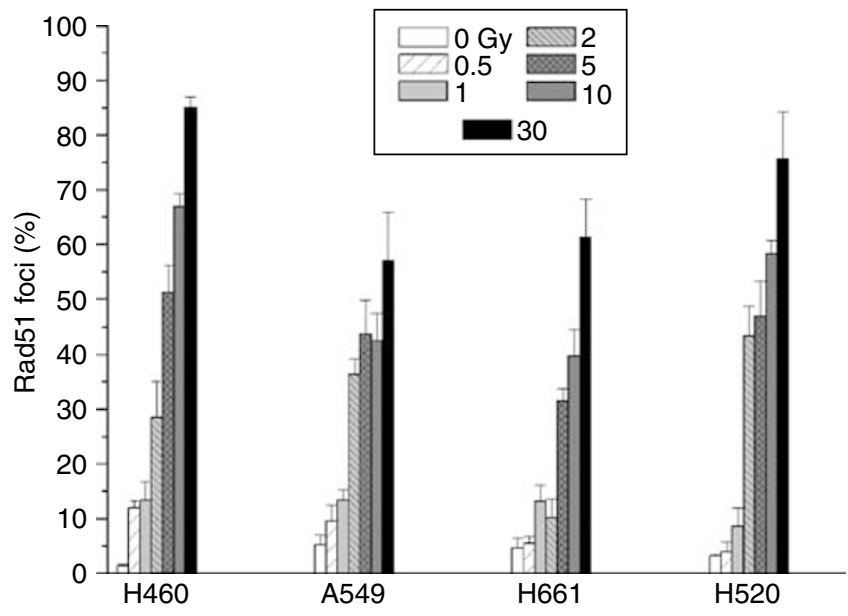

Figure I Radiation-induced Rad5 I foci in NSCLC cell lines. Exponentially growing cells were exposed to $\mathbb{R}(0,0.5, I, 2,5,10$ and $30 \mathrm{~Gy})$ and fixed for foci evaluation $4 \mathrm{~h}$ later. The respective mean values \pm s.e.m. of at least three independent experiments are shown.

number of $\gamma-\mathrm{H} 2 \mathrm{AX}$ foci continue to grow for about $1 \mathrm{~h}$ after irradiation and then decrease slowly over time, consistent with DNA double-strand break repair, but with slower kinetics, with a half-time of about $4 \mathrm{~h}$. The initial number of $\gamma$-H2AX foci per nuclei after irradiation with $10 \mathrm{~Gy}$ was slightly higher for the cell lines with nonfunctional p53 (H661, H520) in comparison to the cell lines with functional p53 (A549, H460). The mean number of $\gamma$ $\mathrm{H} 2 \mathrm{AX}$ foci per nuclei at $0 \mathrm{~h}$ after $10 \mathrm{~Gy}$ was $73.5 \pm 18.5,88.5 \pm 11.5$, $107.5+7.5$ and $123.5+26.5$ for H460, A549, H520 and H661 cells, respectively, whereby the numbers are possibly underestimated for H661 and H520. Both cells also showed high endogenous levels of $\gamma$-H2AX foci relative to A549 and H460. By $24 \mathrm{~h}$ after irradiation, the relative residual damage was significantly reduced in all cell lines studied (Figure 2, Table 1). Cell lines with nonfunctional p53 showed the most relative residual $\gamma-\mathrm{H} 2 \mathrm{AX}$ foci in comparison to the cell lines with functional p53. In addition, residual DNA double-strand breaks have been measured with the FAR assay. There was no evidence for the presence of residual DNA strand breaks $24 \mathrm{~h}$ after irradiation with $30 \mathrm{~Gy}$ in the FAR assay. However, substantial amounts of residual damage were present for all cell lines $4 \mathrm{~h}$ after $30 \mathrm{~Gy}$, with higher residual damage in H661 and $\mathrm{H} 520$, in comparison to the cell lines $\mathrm{H} 460$ and A549 (Table 1). The number of persisting $\gamma$-H2AX foci per nuclei at $24 \mathrm{~h}$ after irradiation with $10 \mathrm{~Gy}$ was by a factor of about 2 higher in comparison to the number of $\operatorname{Rad} 51$ foci. While $40-50 \%$ of the $\gamma$ $\mathrm{H} 2 \mathrm{AX}$ foci were negative for Rad51, more than $80 \%$ of the Rad51 foci were also positive for $\gamma-\mathrm{H} 2 \mathrm{AX}$.

\section{Modulation of Rad51 expression and foci formation}

Treatment of NSCLC cell lines with As-Rad51 resulted in a significant reduction of Rad51 foci in all cell lines and corresponds to a reduction in dose equivalents from $30 \mathrm{~Gy}$ to $<2$ (A549), $\leqslant 5$ (H460, H661) and $\leqslant 10 \mathrm{~Gy}(\mathrm{H} 520)$. Interestingly, pretreatment of NSCLC cell lines with wortmannin, a well-known inhibitor of DNA-PK-dependent NHEJ pathway, increases Rad51 mRNA expression by a factor of about 1.6, but decreases the number of Rad51-positive cells by a factor of about 3 (Figure 3). These data show that radiation-induced formation of locally concentrated Rad51 foci, which are known to represent repair complexes of HR, is not attributable to the level of Rad51 expression and can be effectively inhibited not only with As-ODN targeting Rad51 but also with wortmannin. 


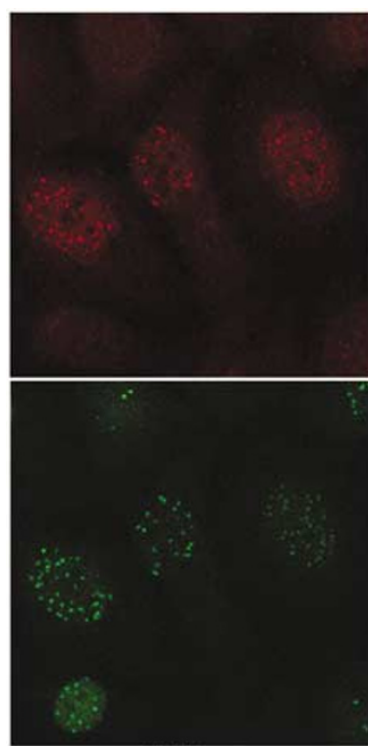

A549

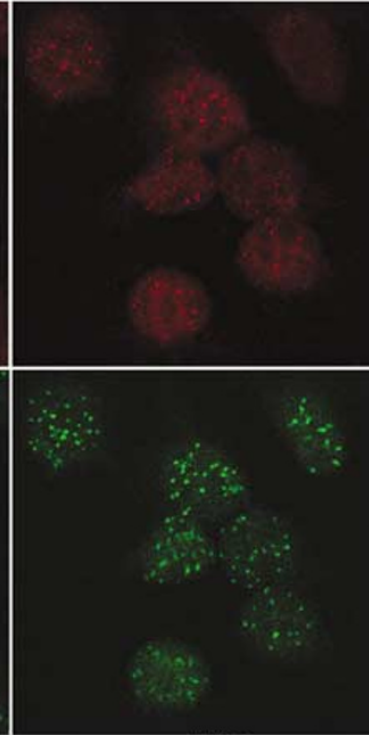

$\mathrm{H} 460$

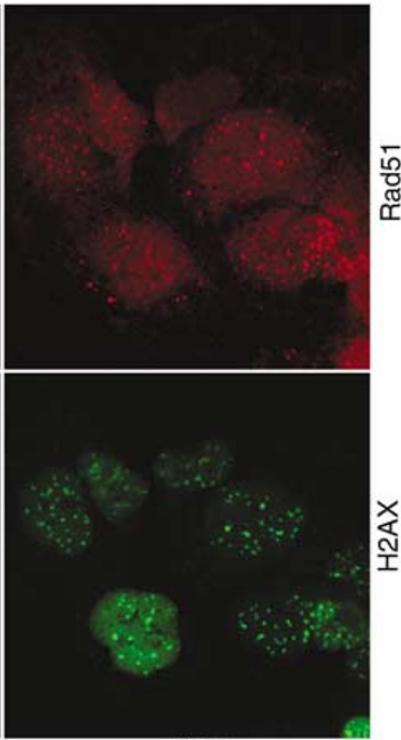

$\mathrm{H} 520$

Figure 2 Radiation-induced Rad5I and $\gamma$-H2AX foci in NSCLC cell lines. Representative immunofluorescence micrographs of Rad5 I (red, Cy-3) and $\gamma-\mathrm{H} 2 \mathrm{AX}$ (green, Alexa-488) are shown at 24h after $10 \mathrm{~Gy}$.

Table I Comparison of residual damage and clonogenic survival in NSCLC cell lines

\begin{tabular}{lrrrc}
\hline & A549 & H460 & H520 & H66I \\
\hline Fraction of residual Dsb (\%) $^{\mathrm{a}}$ & $8.0 \pm 0.3$ & $10.0 \pm 0.4$ & $20.0 \pm 6.0$ & $22.0 \pm 1.3$ \\
Fraction of residual H2AX foci (\%) $^{\mathrm{b}}$ & $19.0 \pm 1.7$ & $19.0 \pm 4.2$ & $38.0 \pm 5.5$ & $67.0 \pm 3.0$ \\
Fraction of residual Rad5I foci (\%) $^{\mathrm{c}}$ & $16.1 \pm 1.9$ & $61.9 \pm 4.0$ & $86.3 \pm 2.0$ & $35.5 \pm 3.8$ \\
Clonogenic survival at 2 Gy $^{\mathrm{d}}$ & $64.6 \pm 4.3$ & $43.7 \pm 2.8$ & $35.5 \pm 4.4$ & $58.6 \pm 5.3$ \\
\hline
\end{tabular}

a Fraction of residual Dsb $(4 \mathrm{~h} / 0 \mathrm{~h})$ after a irradiation dose of $30 \mathrm{~Gy}$, as measured with the FAR assay. ${ }^{b}$ Fraction of residual $\gamma-\mathrm{H} 2 \mathrm{AX}$ foci $(24 \mathrm{~h} / \mathrm{Oh})$ after irradiation with $10 \mathrm{~Gy}$, as measured by $\gamma-\mathrm{H} 2 \mathrm{AX}$ immunfluorescence. 'Fraction of cells with persisting Rad5I foci $(24 \mathrm{~h} / 4 \mathrm{~h})$ after irradiation with $10 \mathrm{~Gy}$, as measured by Rad5Iimmunfluorescence. ${ }^{d}$ Fraction of clonogenic survival after irradiation with $2 \mathrm{~Gy}$.

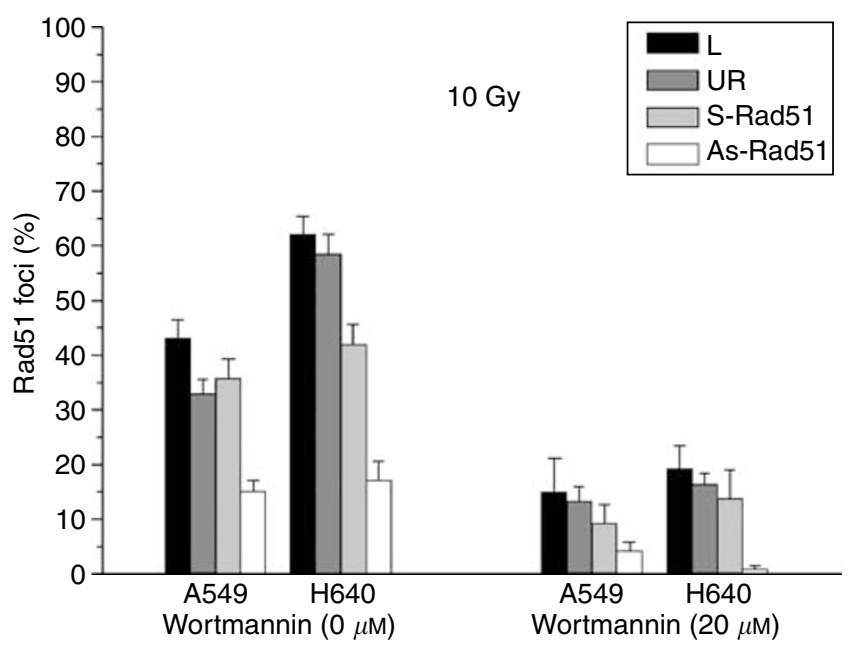

Figure 3 Effect of As-ODN and wortmannin on radiation-induced Rad5 I foci in A549 and H460. Cells were transfected with lipofectamin only (L), UR ODN, sense- (S-Rad5 I) or antisense-ODN targeting Rad5 I (As-Rad5 I), and treated with $20 \mu \mathrm{M}$ wortmannin (W20) or DMSO (W0) I $\mathrm{h}$ before irradiation with $10 \mathrm{~Gy}$. Cells were fixed for foci evaluation at $4 \mathrm{~h}$ after irradiation.
To verify the specificity of the As-ODN, expression of Rad51 mRNA and protein was investigated after treatment with As-ODN. First, the basal expression level of Rad51 at the mRNA and protein levels in NSCLC cell lines was determined. As shown in Figure 4, the expression of Rad51 differed between the exponentially growing cell lines. Interestingly, both cell lines with nonfunctional p53, H661 and H520 in comparison to A549 and H460 with functional p53 show an increased expression of Rad51, both at the mRNA (5-7 folds) and protein (2-3 fold) levels. To test the hypothesis that As-ODN can initiate an RNAse H-mediated degradation of target mRNAs, we quantified the steady-state level of Rad51 mRNA in A549 and H460 cells after transfection with AsRad51. As shown in Figure 5, treatment of H460 and A549 with $300 \mathrm{~nm}$ As-Rad51-3 results in a reduced Rad51 expression to about $65 \%$ with respect to lipofectamin controls.

\section{Effect of As-ODN on induction and rejoining of DNA-Dsb}

In order to outline the role of Rad51-dependent homologous recombination (HR) in the overall rejoining process of Dsb in NSCLC cell lines, rejoining kinetics were assessed in A549 and $\mathrm{H} 460$ over a $4 \mathrm{~h}$ period following exposure of cells to $30 \mathrm{~Gy}$ at $0 \mathrm{~h}$ (initial induction), $1 \mathrm{~h}$ (fast rejoining fraction) and $4 \mathrm{~h}$ (slow rejoining fraction) after transfection with As-ODN specific for Rad51. Figure 6A shows an example for Dsb rejoining of A549 cells after transfection with As-Rad51 and the respective results for both cell lines studied (Figure 6B). In both cell lines studied, no significant changes either in the initial $(0 \mathrm{~h})$ induction levels or in the fraction of Dsb rejoined after 1 and $4 \mathrm{~h}$ was found. These data show that HR has no measurable effect on radiation-induced Dsb rejoining in NSCLC cell lines. However, in order to exclude the possibility that the NHEJ pathway, which is the predominant one in human cells, may mask the role of HR in Dsb rejoining, cells were treated with wortmannin, a potent inhibitor of the NHEJ pathway, or As-ODN targeting DNA-PKcs. Treatment with $20 \mu \mathrm{M}$ wortmannin $1 \mathrm{~h}$ before irradiation with $30 \mathrm{~Gy}$ or As-DNA-PKcs increased the fraction of nonrepaired Dsb at $4 \mathrm{~h}$ after irradiation (Sak et al, 2002). If these nonrejoined Dsb are preferentially repaired via the HR pathway, combined pretreatment of cells with As-Rad51 and wortmannin or As-DNA-PKcs then should additionally increase the fraction of nonrejoined Dsb. However, 
A

$510152020510152020 \quad 510152020510152020$

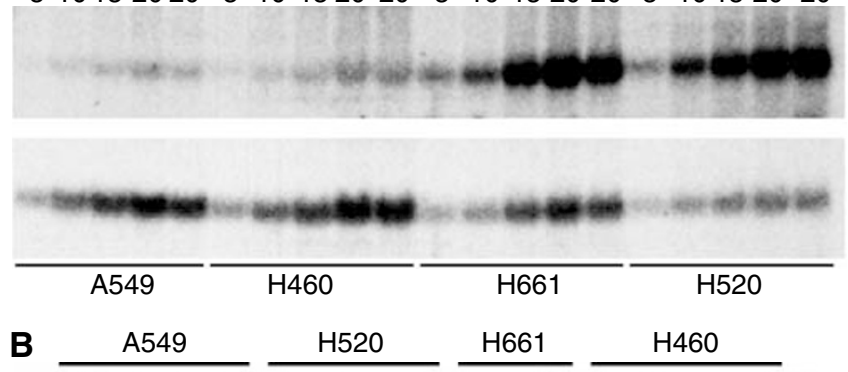

B

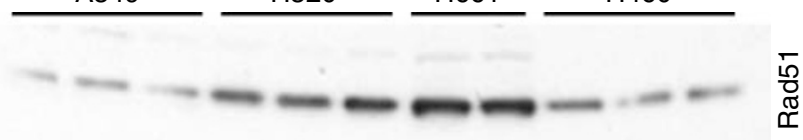

$---\infty-\infty-\infty-\infty$

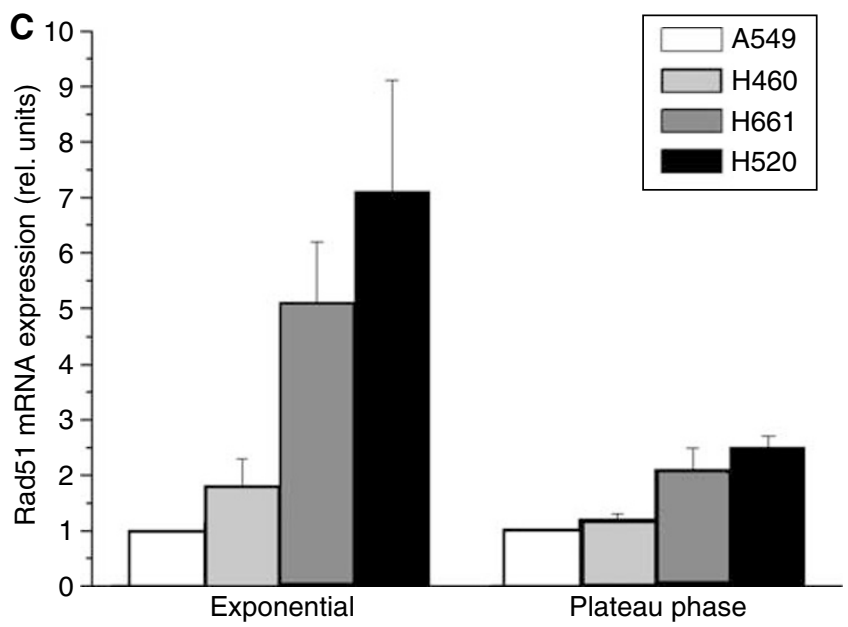

Figure 4 Representative hybridisation blots for the expression of Rad5 I mRNA (A) and protein (B) in NSCLC cell lines are shown. Different amounts of total RNA $(5-20 \mu \mathrm{g})$ and protein $(40 \mu \mathrm{g})$ for each exponentially growing cell line were loaded onto the gel and hybridised with DNA probes or antibodies targeting Rad5I and $\beta$-actin. Data were normalised to the $\beta$-actin signal to correct for gel loading and differences in overall mRNA and protein expression. (C) Mean values + s.e.m. of at least three independent experiments for the relative level of Rad5 I expression in NSCLC cell lines under exponential and plateau phase growth conditions are shown.

combined pretreatment of cells with As-Rad51 and wortmannin or As-DNA-PK in comparison to the single-treatment schedule did not significantly influence the fractions of nonrejoined Dsb, either at 1 or at $4 \mathrm{~h}$ after irradiation. In conclusion, these data show that treatment of NSCLC cell lines with antisense ODN targeting Rad51 mRNA was not effective with respect to rejoining of radiationinduced Dsb, irrespective of whether the DNA-PKcs-mediated NHEJ pathway was active or not.

\section{Role of Rad51-dependent HR for the radiosensitivity of NSCLC cell}

In order to examine the relation between the Rad51-dependent repair activity, that is, formation of Rad51-containing repair complexes and survival, the fraction of apoptotic cells after a radiation dose of $20 \mathrm{~Gy}$ and clonogenic survival at $2 \mathrm{~Gy}$ (SF2) were
A

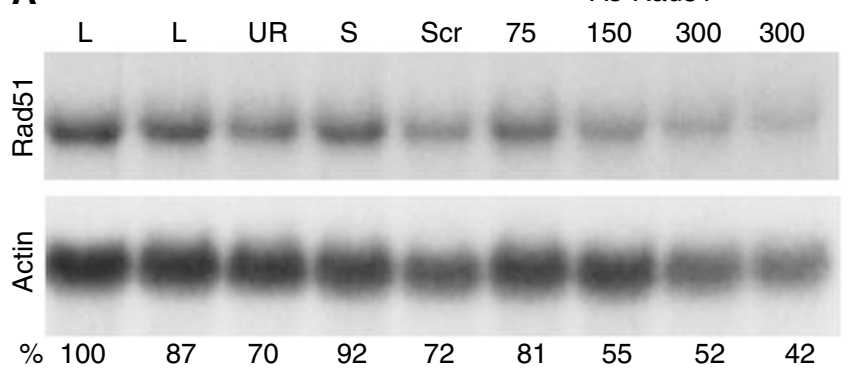

B
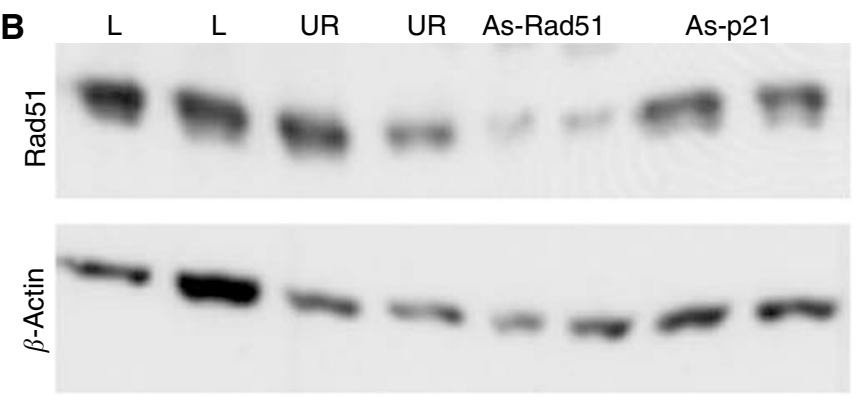

Figure 5 Representative hybridisation blots for the effect of As-Rad5 I on the expression of Rad5 I mRNA $(\mathbf{A})$ and Rad5I protein $(\mathbf{B})$ are shown. Cells were transfected for $24 \mathrm{~h}$ with lipofectamin only (L), UR ODN and As-ODN targeting Rad5I (As-rad5I). As-p2I targeting p2 I ${ }^{\text {wafl/cipl }}$ (Sak et al, 2003) was used to show the specificity of the ODN used. Data were normalised to the $\beta$-actin signal to correct for gel loading and differences in overall gene expression.

determined. To evaluate the role of HR in the radiosensitivity of NSCLC cell lines, expression level of Rad51, fraction of Rad51 foci after irradiation as a functional test for Rad51 and the SF2 data have been compared in all the four NSCLC cell lines. Overall, there was no correlation between the SF2, as a measure for the intrinsic radiosensitivity, and the level of Rad51 expression or the fraction of Rad51 foci formation at $4 \mathrm{~h}$ after irradiation. Likewise, there was no correlation between SF2 and the fraction of residual $\gamma$-H2AX measured as the ratio of $\gamma-\mathrm{H} 2 \mathrm{AX}$ foci at 0 and $24 \mathrm{~h}$ after irradiation with $10 \mathrm{~Gy}$. However, the relative fraction of Rad51 foci remaining at $24 \mathrm{~h}$ (percentage of Rad51 foci at $24 \mathrm{~h} /$ percentage of Rad51 at $4 \mathrm{~h}$ ) is a more reliable factor for the radiosensitivity of NSCLC cell lines (Figure 7).

Even though the basal expression level and the percentage of Rad51 at early times after IR did not determine the radiosensitivity of NSCLC cell lines, the effect of decreased expression of Rad51 within an individual cell line may be more detrimental. In order to measure the effect of a selective Rad51 modulation within a given cell line, As-Rad51 were used. As shown in Figure 8, transfection with $300 \mathrm{~nm}$ As-Rad51 increased the fraction of apoptotic cells in all cell lines after irradiation with $20 \mathrm{~Gy}$. However, increased apoptotic death of sham-irradiated cells was also evident. Even so, there is a significant increase of radiation-induced apoptosis in cells treated with As-Rad51.

\section{DISCUSSION}

Repair of radiation-induced DNA double-strand breaks in mammalian cells has been thought to process mainly through the NHEJ, with DNA-PK being the central repair protein complex for this pathway. Nevertheless, HR, the most important repair pathway for Dsb in yeast, also contributes to the repair of Dsb in vertebrate cells (Sonoda et al, 2001) and is essential for their viability. Inactivation of the key HR protein Rad51 in chicken 
A
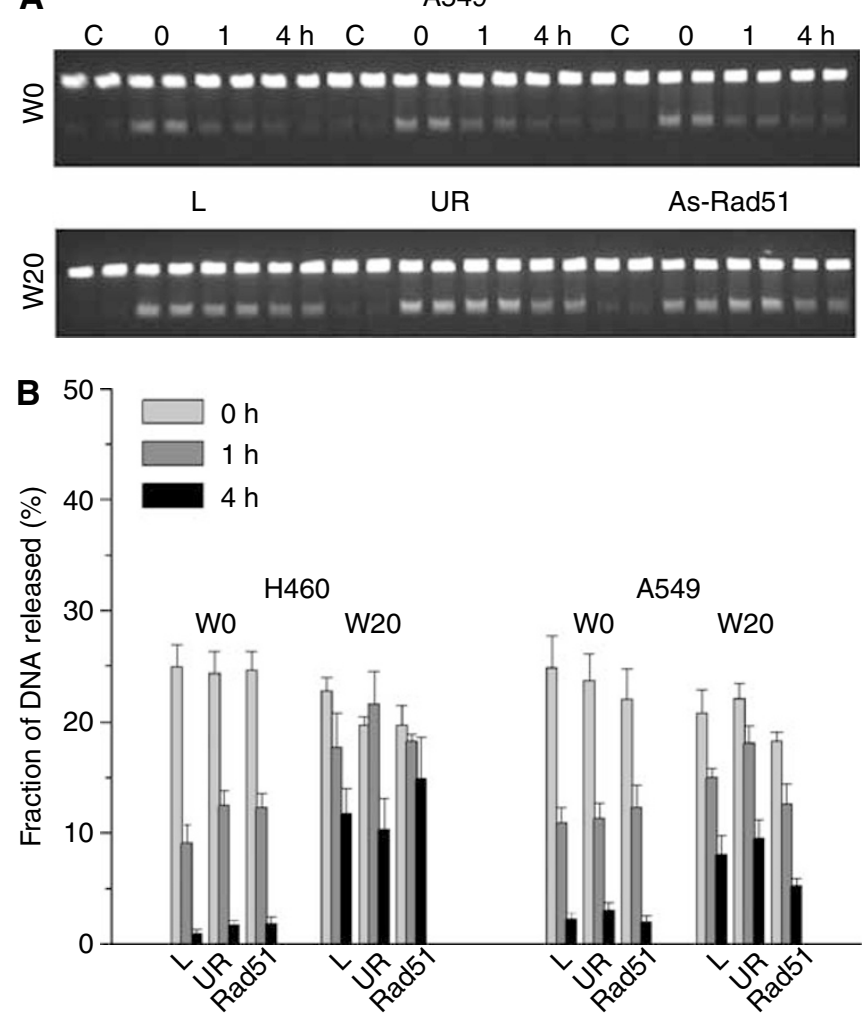

Figure 6 Rejoining of DNA-DSB in NSCLC cell lines treated with AsODN. Constant-field gel electrophoresis showing the rejoining of IRinduced DNA-DSB in A549 cells after transfection with As-ODN (A). The fractions of DNA released into the gel as a measure for DNA Dsb at 0, I and $4 \mathrm{~h}$ after transfection and irradiation with $30 \mathrm{~Gy}$ are shown for A549 and H460 (B). Sham-irradiated controls (C) and irradiated cells previously transfected with lipofectamin only $(\mathrm{L})$, UR ODN and As-ODN targeting Rad5I (As-rad5I). Cells were treated with $20 \mu \mathrm{M}$ wortmannin (W20) or DMSO (WO) I h prior to irradiation with $30 \mathrm{~Gy}$.

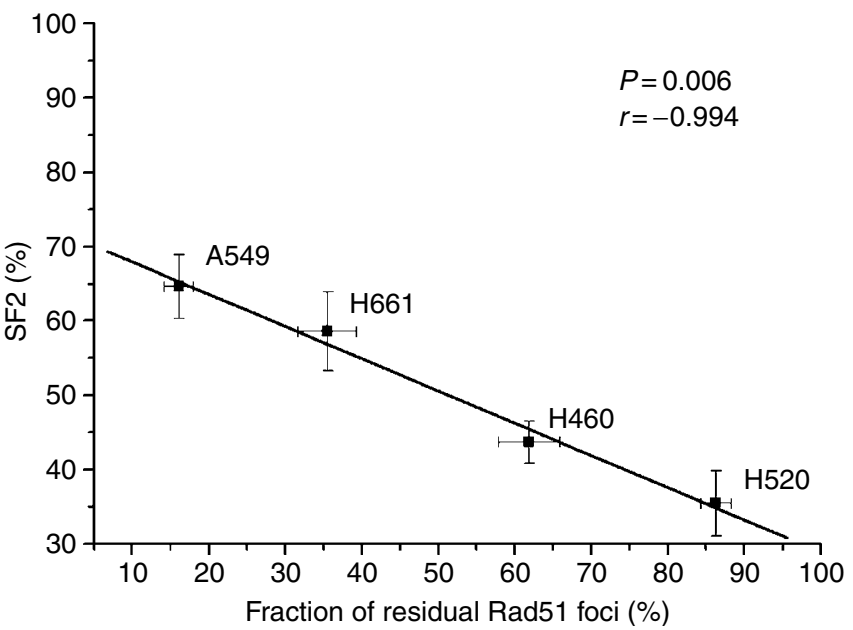

Figure 7 Relationship between the fraction of residual Rad5I foci remaining at $24 \mathrm{~h}$ (relative to the maximum level of Rad5 I foci at $4 \mathrm{~h}$ ) after irradiation with 10 Gy and clonogenic survival at 2 Gy (SF2) in NSCLC cell lines. A linear fit through the data points indicates an inverse relation between the fraction of remaining Rad5I foci and SF2 $(P=0.006$ $r=-0.994)$

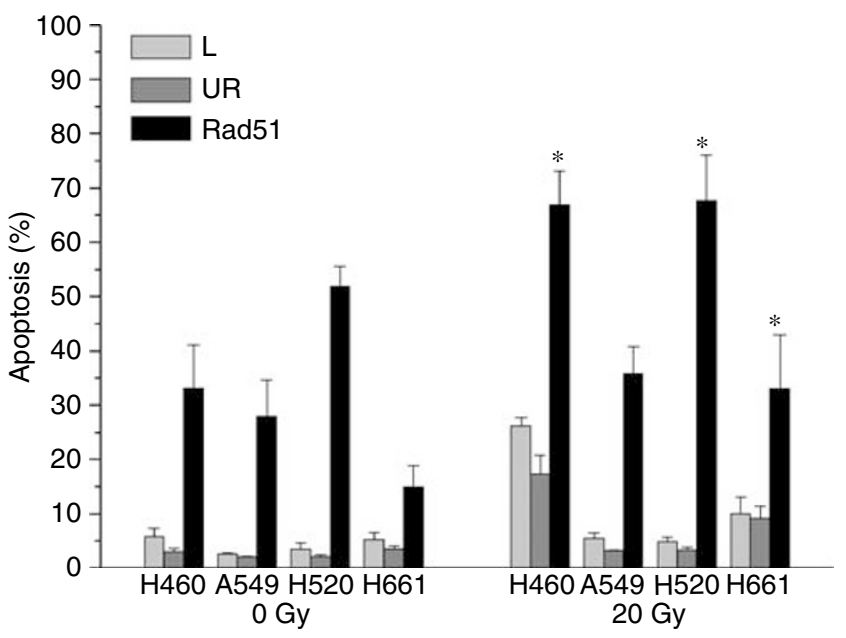

Figure 8 Radiation-induced apoptosis in NSCLC cell lines at $24 \mathrm{~h}$ following $20 \mathrm{~Gy}$ and transfection with lipofectamin (L), $300 \mathrm{nM}$ UR and antisense Rad5I (Rad5I) oligonucleotides, with a significant (*) difference between irradiated and nonirradiated cells ( $<0.05, t$-test).

lymphocytes leads to an accumulation of cells in the G2/M with subsequent increase of chromosome aberrations prior to cell death (Sonoda et al, 1998). In the same way, murine cells deficient in Rad51 are nonviable (Tsuzuki et al, 1996). In comparison, cells overexpressing Rad51 showed higher recombination frequencies (Lambert and Lopez, 2001), reduced DNA break frequencies, translocations, chromosome aberrations, decreased induction of apoptosis (Grandy et al, 2002; Raderschall et al, 2002b), stimulated tumorigenesis (Bertrand et al, 2003) and increased resistance to IR (Vispe et al, 1998).

To evaluate the role of Rad51 in the radiosensitivity of NSCLC cell lines and the rejoining process of radiation-induced Dsb, expression of Rad51 was modulated with As-ODN targeting Rad51. Since complete loss of Rad51 gene expression leads to cell death in vertebrate cells, the use of As-ODN represents a rational tool and an opportunity to analyse the impact of the modulation of Rad51dependent homologous recombination pathway in the radiosensitivity of human NSCLC cell lines. After a moderate downregulation of Rad 51 expression to about $60 \%$ of the nontransfected cells, the formation of Rad51 foci, overall rejoining of Dsb, induction of apoptosis and clonogenic survival were evaluated after exposure of NSCLC cell lines to IR. In addition, $\gamma$-H2AX foci formation as a measure for DNA double-strand breaks and its colocalisation with Rad51 were also evaluated.

The present data demonstrate a dose- and time-dependent increase in the percentage of cells with Rad51 foci in NSCLC cell lines. Cell lines with nonfunctional p53, in comparison to the cell lines with functional p53, show a higher expression level of Rad51 at the mRNA level by a factor of about 2 and 5 in G1- and G2enriched populations, respectively. It has been previously shown that wild-type p53 protein downregulates the level of Rad51 expression in primary cells (Xia et al, 1997). Reduced expression of Rad51 and reduced spontaneous formation of Rad51 foci have also been found in $\mathrm{p} 53^{+7+}$ in comparison to $\mathrm{p} 53^{-1-}$ primary mouse embryonic fibroblasts (Kumari et al, 2004). The activity of Rad51 was shown to be regulated by a transcription-independent direct protein-protein interaction with p53 (Linke et al, 2003). In cases where p53 is absent or mutated, Rad51 has been shown to have an increased recombination activity. In the present study, however, the high expression level of Rad51 found in cell lines with nonfunctional p53 is not reflected by a high fraction of Rad51 focipresenting cells. Instead, the proliferation status of tumour cell lines primarily determines the formation of Rad51 foci after IR. 
Higher expression of Rad51 by a factor of about 2 and a high fraction of Rad51 foci in proliferating $(>40 \%)$, in comparison to G1-enriched, confluent populations $(<5 \%)$ was also found in NSCLC cell lines, irrespective of the p53 status. A clear cell-cycledependent expression of Rad51 foci has also been found in previous studies with higher fraction of Rad51 foci-presenting cells in the S- and G2-phases in comparison to the G1-phase (Yamamoto et al, 1996; Yuan et al, 2003). The highest fraction of Rad51 foci was found at $4-6 \mathrm{~h}$ after irradiation, a time where most of the initially radiation-induced Dsb are rejoined via the DNA-PK dependent non-HR mechanism. After this time, the percentage of cells with Rad51 foci gradually decreases. A high fraction of cells with persisting Rad51 foci at $24 \mathrm{~h}$ after irradiation was found in radiosensitive cell lines. These persisting rad51 foci possibly reflect Dsb rejoining products sensing the recruitment of HR pathway, obviously with different efficacy in the NSCLC cell lines studied.

In order to explore the possibility that residual Rad51 foci reflect nonrepaired DNA double-strand breaks, phosphorylation of histone $\gamma-\mathrm{H} 2 \mathrm{AX}$ in response to DNA double-strand breaks produced by IR has been measured, which is proposed to concentrate repair factors at sites of DNA damage (Celeste et al, 2003). Although differences in the loss of $\gamma-\mathrm{H} 2 \mathrm{AX}$ foci have been found to be related in part to the intrinsic radiosensitivity of cervical cancer cell lines (Banath et al, 2004), our data did not support these observations. A co-localisation frequency of more than $80 \%$ for Rad51 and $\gamma$-H2AX foci elucidate that persisting Rad51 foci mostly contains DNA double-strand breaks. However, the Rad51-positive foci, in comparison to the H2AX-positive but Rad51-negative foci, obviously have more correlative power for the radiation sensitivity of lung cancer cell lines.

Treatment of exponentially growing cells with As-Rad51 significantly reduces the percentage of cells with Rad51 foci in all NSCLC cell lines, but did not change the fate of Dsb rejoining in the FAR assay. Therefore, no indication of an involvement of Rad51 in the direct rejoining process of radiation-induced Dsb is evident from these data. Even under the condition where the NHEJ pathway is disabled with wortmannin, As-Rad51 has no measurable effect on Dsb rejoining. However, at concentrations resulting in a significant inhibition of DNA-PK-dependent NHEJ, wortmannin also inhibits ATM (Sarkaria et al, 1998). It has been shown that ATM regulates other proteins known to play a role in DNA-repair, cell-cycle regulation and radiation sensitivity, including p53, CHK2, BRCA1 and NBS1 (Canman et al, 1998; Cortez et al, 1999), and is required for the assembly of Rad51 foci (Chen et al, 1999; Yuan et al, 2003). Therefore, wortmannin should not only affect NHEJ through inhibition of DNA-PK activity in NSCLC cell lines (Sak et al, 2002), but also HR via inhibition of ATM-dependent formation of Rad51 foci. Conflicting results regarding the effect of wortmannin on HR has been published, with an increase (Delacote et al, 2002) and a decrease of HR (Paull et al, 2000; Allen et al, 2003). Our results, however, show an efficient inhibition of Rad51 foci formation after treatment with wortmannin, which in part explains its higher effect on the clonogenic survival of NSCLC cell lines when compared to a treatment schedule using As-ODN targeting DNA-PKcs (Sak et al, 2002). Inhibition of Rad51 foci with wortmannin is not a result of reduced Rad51 expression, but is obviously regulated at the post-translational level, because treatment with wortmannin leads to an increased expression of Rad51 mRNA. The observed effect of wortmannin on NHEJ, HR and cell survival is obviously the result of noncompetitive and covalent binding of wortmannin to the kinase region of DNA-PKcs protein (Izzard et al, 1999). The formation of covalent adducts may therefore prevent the dissociation of DNA-PKcs from the DNA ends, and thereby block both HR and NHEJ. Alternatively, but not exclusively, wortmannin may inhibit HR through inactivation of ATM, and thereby prevents Rad51 foci formation. Nevertheless, a selective inactivation of NHEJ via As-ODN targeting DNA-PKcs, the key repair protein of NHEJ, also did not change the Dsb rejoining response of NSCLC cell lines to As-Rad51 treatment. Therefore, no contribution of Rad51-dependent HR in the direct removal of radiation-induced Dsb as measured by the FAR assay is evident from these data. In this respect, Wang et al (2001) also have shown that HR did not measurably contribute to the removal of radiation-induced Dsb, even under conditions where NHEJ is compromised.

Despite the obvious missing of an involvement of Rad51 in the direct rejoining process of radiation-induced Dsb, loss of Rad51 has a deleterious effect on cell survival (Tsuzuki et al, 1996; Sonoda et al, 1998). In the same manner, downregulation of Rad51 foci formation has been shown to increase apoptotic cell death (Raderschall et al, 2002b). Our data support these observations and show that treatment of NSCLC cell lines with As-Rad51 increases radiation-induced apoptosis. Interestingly, the most apoptosis-proficient cell lines after As-Rad51 treatment are H520 and $\mathrm{H} 460$, both cell lines with high Rad51 foci remaining at $24 \mathrm{~h}$ after irradiation.

Even though Rad51 is expressed at higher levels in tumour cells as compared with normal cells (Raderschall et al, 2002a), modulation of Rad51 expression has been shown to be more susceptible in tumour cells (Russell et al, 2003). The increased expression of Rad51 found in tumour cells can be partially attributed to the higher proliferating fraction of tumour cells, because a higher expression of Rad51 mRNA by a factor of about 2 in exponentially growing, in comparison to confluent, NSCLC cell lines is evident from the present study. Nevertheless, the different regulatory processes of Rad51 in normal and tumour cells (Russell et $a l, 2003)$ and its role in radiosensitivity offer the possibility for a selective targeting of radiotherapy.

In conclusion, these data demonstrate that human NSCL cell lines have the same percentage of cells with Rad51 foci at early times after IR, albeit the significant differences in Rad51 expression. Therefore, differences in Rad51 expression alone did not determine the proficiency of Rad51 foci formation. Instead, cell cycle distributions at the irradiation time primarily affect the formation of IR-induced Rad51 foci. Downregulation of Rad51 expression within a specific cell line decreases the fraction of Rad51 foci-presenting cells and significantly increases radiationinduced apoptotic cell death. The relative level of persisting Rad51 foci measured $24 \mathrm{~h}$ after irradiation neither correlates to the relative level of persisting $\gamma-\mathrm{H} 2 \mathrm{AX}$ foci nor to the residual level of DNA double-strand breaks, but was significantly correlated with SF2.

\section{ACKNOWLEDGEMENTS}

This research was supported by grants from the Deutsche Krebshilfe, 10-1389.

\section{REFERENCES}

Allen C, Halbrook J, Nickoloff JA (2003) Interactive competition between homologous recombination and non-homologous end joining. Mol Cancer Res 1: $913-920$
Banath JP, MacPhail SH, Olive PL (2004) Radiation sensitivity, H2AX phosphorylation, and kinetics of repair of DNA strand breaks in irradiated cervical cancer cell lines. Cancer Res 64: 7144-7149 
Bertrand P, Lambert S, Joubert C, Lopez BS (2003) Overexpression of mammalian Rad51 does not stimulate tumorigenesis while a dominant-negative Rad51 affects centrosome fragmentation, ploidy and stimulates tumorigenesis, in p53-defective $\mathrm{CHO}$ cells. Oncogene 22: $7587-7592$

Bishop DK, Ear U, Bhattacharyya A, Calderone C, Beckett M, Weichselbaum RR, Shinohara A (1998) Xrcc3 is required for assembly of Rad51 complexes in vivo. J Biol Chem 273: 21482-21488

Burgess TL, Fisher EF, Ross SL, Bready JV, Qian YX, Bayewitch LA, Cohen AM, Herrera CJ, Hu SS, Kramer TB, Lott FD, Martin FH, Pierce GF, Simonet L, Farrell CL (1995) The antiproliferative activity of c-myb and c-myc antisense oligonucleotides in smooth muscle cells is caused by a nonantisense mechanism. Proc Natl Acad Sci USA 92: $4051-4055$

Canman CE, Lim DS, Cimprich KA, Taya Y, Tamai K, Sakaguchi K, Appella E, Kastan MB, Siliciano JD (1998) Activation of the ATM kinase by ionizing radiation and phosphorylation of p53. Science 281: $1674-1677$

Celeste A, Fernandez-Capetillo O, Kruhlak MJ, Pilch DR, Staudt DW, Lee A, Bonner RF, Bonner WM, Nussenzweig A (2003) Histone H2AX phosphorylation is dispensable for the initial recognition of DNA breaks. Nat Cell Biol 5: 675-679

Chen G, Yuan SS, Liu W, Xu Y, Trujillo K, Song B, Cong F, Goff SP, Wu Y, Arlinghaus R, Baltimore D, Gasser PJ, Park MS, Sung P, Lee EY (1999) Radiation-induced assembly of Rad51 and Rad52 recombination complex requires ATM and c-Abl. J Biol Chem 274: 12748-12752

Collis SJ, Tighe A, Scott SD, Roberts SA, Hendry JH, Margison GP (2001) Ribozyme minigene-mediated RAD51 down-regulation increases radiosensitivity of human prostate cancer cells. Nucleic Acids Res 29: $1534-1538$

Cortez D, Wang Y, Qin J, Elledge SJ (1999) Requirement of ATM-dependent phosphorylation of brca 1 in the DNA damage response to double-strand breaks. Science 286: $1162-1166$

Delacote F, Han M, Stamato TD, Jasin M, Lopez BS (2002) An xrcc4 defect or Wortmannin stimulates homologous recombination specifically induced by double-strand breaks in mammalian cells. Nucleic Acids Res 30: 3454-3463

Flygare J, Benson F, Hellgren D (1996) Expression of the human RAD51 gene during the cell cycle in primary human peripheral blood lymphocytes. Biochim Biophys Acta 1312: $231-236$

Golub EI, Gupta RC, Haaf T, Wold MS, Radding CM (1998) Interaction of human rad51 recombination protein with single-stranded DNA binding protein, RPA. Nucleic Acids Res 26: 5388-5393

Grandy I, Hardt T, Schmid M, Haaf T (2002) Effects of higher-order nuclear structure and Rad51 overexpression on radiation-induced chromosome rearrangements. Cytogenet Genome Res 98: 265-269

Gupta RC, Golub EI, Wold MS, Radding CM (1998) Polarity of DNA strand exchange promoted by recombination proteins of the RecA family. Proc Natl Acad Sci USA 95: 9843-9848

Haaf T, Golub EI, Reddy G, Radding CM, Ward DC (1995) Nuclear foci of mammalian Rad51 recombination protein in somatic cells after DNA damage and its localization in synaptonemal complexes. Proc Natl Acad Sci USA 92: 2298-2302

Iotsova V, Stehelin D (1995) Antisense p53 provokes changes in HeLa cell growth and morphology. Eur J Cell Biol 68: 122-132

Izzard RA, Jackson SP, Smith GC (1999) Competitive and noncompetitive inhibition of the DNA-dependent protein kinase. Cancer Res 59: $2581-$ 2586

Johnson RD, Jasin M (2001) Double-strand-break-induced homologous recombination in mammalian cells. Biochem Soc Trans 29: 196-201

Kanaar R, Hoeijmakers JHJ, vanGent DC (1998) Molecular mechanism of DNA double-strand break repair. Trends Cell Biol 8: 483-489

Kumari A, Schultz N, Helleday T (2004) p53 protects from replicationassociated DNA double-strand breaks in mammalian cells. Oncogene 23: $2324-2329$

Lambert S, Lopez BS (2001) Role of RAD51 in sister-chromatid exchanges in mammalian cells. Oncogene 20: 6627-6631

Leuther KK, Hammersten O, Kornberg RD, Chu G (1999) Structure of DNA-dependent protein kinase: implications for its regulation by DNA. EMBO J 18: $1114-1123$

Linke SP, Sengupta S, Khabie N, Jeffries BA, Buchhop S, Miska S, Henning W, Pedeux R, Wang XW, Hofseth LJ, Yang Q, Garfield SH, Sturzbecher HW, Harris CC (2003) p53 interacts with hRAD51 and hRAD54, and directly modulates homologous recombination. Cancer Res 63: $2596-2605$
Liu Y, Li M, Lee EY, Maizels N (1999) Localization and dynamic relocalization of mammalian Rad52 during the cell cycle and in response to DNA damage. Curr Biol 9: 975-978

Ohnishi T, Taki T, Hiraga S, Arita N, Morita T (1998) In vitro and in vivo potentiation of radiosensitivity of malignant gliomas by antisense inhibition of the RAD51 gene. Biochem Biophys Res Commun 245: $319-324$

Paull TT, Rogakou EP, Yamazaki V, Kirchgessner CU, Gellert M, Bonner WM (2000) A critical role for histone H2AX in recruitment of repair factors to nuclear foci after DNA damage. Curr Biol 10: 886-895

Raderschall E, Bazarov A, Cao J, Lurz R, Smith A, Mann W, Ropers HH, Sedivy JM, Golub EI, Fritz E, Haaf T (2002a) Formation of higher-order nuclear Rad51 structures is functionally linked to p21 expression and protection from DNA damage-induced apoptosis. J Cell Sci 115: $153-164$

Raderschall E, Stout K, Freier S, Suckow V, Schweiger S, Haaf T (2002b) Elevated levels of Rad51 recombination protein in tumor cells. Cancer Res 62: 219-225

Russell JS, Brady K, Burgan WE, Cerra MA, Oswald KA, Camphausen K, Tofilon PJ (2003) Gleevec-mediated inhibition of Rad51 expression and enhancement of tumor cell radiosensitivity. Cancer Res 63: $7377-7383$

Sak A, Stuschke M, Wurm R, Schroeder G, Sinn B, Wolf G, Budach V (2002) Selective inactivation of DNA-dependent protein kinase with antisense oligodeoxynucleotides: consequences for the rejoining of radiationinduced DNA double-strand breaks and radiosensitivity of human cancer cell lines. Cancer Res 62: 6621-6624

Sak A, Wurm R, Elo B, Grehl S, Pottgen C, Stuben G, Sinn B, Wolf G, Budach V, Stuschke M (2003) Increased radiation-induced apoptosis and altered cell cycle progression of human lung cancer cell lines by antisense oligodeoxynucleotides targeting p53 and p21(WAF1/CIP1). Cancer Gene Ther 10: 926-934

Sarkaria JN, Tibbetts RS, Busby EC, Kennedy AP, Hill DE, Abraham RT (1998) Inhibition of phosphoinositide 3-kinase related kinases by the radiosensitizing agent wortmannin. Cancer Res 58: 4375-4382

Shinohara A, Ogawa H, Matsuda Y, Ushio N, Ikeo K, Ogawa T (1993) Cloning of human, mouse and fission yeast recombination genes homologous to RAD51 and recA. Nat Genet 3: 239-243

Smith GCM, Jackson SP (1999) The DNA-dependent protein kinase. Genes Dev 13: 916-934

Sonoda E, Sasaki MS, Buerstedde JM, Bezzubova O, Shinohara A, Ogawa H, Takata M, Yamaguchi-Iwai Y, Takeda S (1998) Rad51-deficient vertebrate cells accumulate chromosomal breaks prior to cell death. EMBO J 17: 598-608

Sonoda E, Takata M, Yamashita YM, Morrison C, Takeda S (2001) Homologous DNA recombination in vertebrate cells. Proc Natl Acad Sci USA 98: 8388-8394

Stuschke M, Sak A, Wurm R, Sinn B, Wolf G, Stüben G, Budach V (2002) Radiation induced apoptosis in human non-small-cell lung cancer cell lines is secondary to cell-cycle progression beyond the G2-phase checkpoint. Int J Radiat Biol 78: 807-819

Taki T, Ohnishi T, Yamamoto A, Hiraga S, Arita N, Izumoto S, Hayakawa $\mathrm{T}$, Morita T (1996) Antisense inhibition of the RAD51 enhances radiosensitivity. Biochem Biophys Res Commun 223: 434-438

Tan TL, Essers J, Citterio E, Swagemakers SM, de Wit J, Benson FE, Hoeijmakers JH, Kanaar R (1999) Mouse Rad54 affects DNA conformation and DNA-damage-induced Rad51 foci formation. Curr Biol 9: $325-328$

Tashiro S, Kotomura N, Shinohara A, Tanaka K, Ueda K, Kamada N (1996) $S$ phase specific formation of the human Rad51 protein nuclear foci in lymphocytes. Oncogene 12: 2165-2170

Tsuzuki T, Fujii Y, Sakumi K, Tominaga Y, Nakao K, Sekiguchi M, Matsushiro A, Yoshimura Y, Morita T (1996) Targeted disruption of the Rad51 gene leads to lethality in embryonic mice. Proc Natl Acad Sci USA 93: $6236-6240$

van Gent DC, Hoeijmakers JH, Kanaar R (2001) Chromosomal stability and the DNA double-stranded break connection. Nat Rev Genet 2: 196-206

Vispe S, Cazaux C, Lesca C, Defais M (1998) Overexpression of Rad51 protein stimulates homologous recombination and increases resistance of mammalian cells to ionizing radiation. Nucleic Acids Res 26: 28592864

Wang H, Zeng ZC, Bui TA, Sonoda E, Takata M, Takeda S, Iliakis G (2001) Efficient rejoining of radiation-induced DNA double-strand breaks in vertebrate cells deficient in genes of the RAD52 epistasis group. Oncogene 20: 2212-2224 
Xia SJ, Shammas MA, Shmookler Reis RJ (1997) Elevated recombination in immortal human cells is mediated by HsRAD51 recombinase. Mol Cell Biol 17: 7151-7158

Yamamoto A, Taki T, Yagi H, Habu T, Yoshida K, Yoshimura Y, Yamamoto K, Matsushiro A, Nishimune Y, Morita T (1996) Cell cycle-dependent expression of the mouse Rad51 gene in proliferating cells. Mol Gen Genet 251: $1-12$

Yuan SS, Chang HL, Lee EY (2003) Ionizing radiation-induced Rad51 nuclear focus formation is cell cycle-regulated and defective in both $\operatorname{ATM}(-/-)$ and c-Abl $(-/-)$ cells. Mutat Res 525: 85-92 